\title{
KUALITAS PELAYANAN TERHADAP KEPUASAN PENUMPANG KERETA API PRAMEKS DI STASIUN KLATEN
}

\author{
Tri Widodo ${ }^{1}$ Andung Jati Nugroho ${ }^{2}$ \\ Program Studi Teknik Industri Universitas Teknologi Yogyakarta \\ colbikul26@gmail.com, andung.nugroho@staff.uty.ac.id
}

\begin{abstract}
PT Kereta Api Indonesia provides services to prospective passengers in the provision of services related to the only railway services in Indonesia. In this study aims to determine the extent of the quality of service that has been given by Klaten Station to train passengers. This research was carried out on trainers. The study was conducted by distributing 25 questionnaires to train passengers at Klaten Station. Then tested the validity and reliability, to determine the suitability of the distributed questionnaire, then measured the level of importance with Service Performance, then carried out the calculation of the Customer Satisfaction Index to determine the level of passenger satisfaction, then make a chart Importance Performance Analysis to determine the level of importance and customer satisfaction. The calculation results from Service Performance obtained the value of the suitability level of $44.45 \%-77.45 \%$, the value of the Customer Satisfaction Index of $61.60 \%$ which is included in the Very Poor's criteria or needs to be improved, the Importance Performance Analysis calculation has the highest priority quality attributes namely the attributes number 6, 7, 12, 20, and 21. With the proposed improvements using the Theory Resheniya Izobreatatelskikh Zadatch, that is, increase the number of seats for prospective passengers and introductory. Adding supporting facilities that do not yet exist in the Klaten Station environment, PT KAl will educate Klaten Station officers to be more disciplined and prioritize the best service to customers.
\end{abstract}

Keywords: servqual, customer, satisfaction, performance, importance

\begin{abstract}
Abstrak
PT Kereta Api Indonesia memberikan pelayanan kepada calon penumpang dalam penyediaan jasa yangberhubungan dengan pelayanan perkeretaapian satu-satunya di Indonesia. Pada penelitian ini bertujuan untuk mengetahui sejauh mana kualitas pelayanan yang sudah diberikan oleh Stasiun Klaten terhadap penumpang kereta api. Penelitian ini dilakukan pada penumpang kereta. Penelitian dilakukan dengan menyebarkan 25 kuesioner kepada para penumpang kereta api di Stasiun Klaten. Kemudian dilakukan uji validitas dan reliabilitas, untuk menentukan kesesuaian kuesioner yang disebar, selanjutnya dilakukan pengukuran rata-rata tingkat kepentingan dengan Service Performance, selanjutnya dilakukan perhitungan Customer Satisfaction Index untuk mengetahui tingkat kepuasan penumpang, kemudian dilakukan pembuatan grafik Importance Performance Analysis untuk menentukan tingkat kepentingan dan kepuasan pelanggan. Hasil perhitungan dari Service Performance didapatkan nilai tingkat kesesuaian sebesar $44,45 \%-77,45 \%$, nilai Customer Satisfaction Index sebesar $61,60 \%$ yang termasuk dalam kriteria Very Poor atau perlu dilakukan perbaikan, perhitungan Importance Performance Analysis terdapat atribut kualitas yang menjadi prioritas utama yaitu atribut nomor $6,7,12,20$, dan 21. Dengan usulan perbaikan menggunakan teoriya Resheniya Izobreatatelskikh Zadatch yaitu, memberi nomer antrian kepada para pelanggan saat membeli tiket, menambah jumlah kursi untuk calon penumpang dan pengantar, Menambah fasilitas penunjang yang belum ada dilingkungan Stasiun Klaten, PT KAI akan memberi penyuluhan kepada para petugas Stasiun Klaten agar lebih disiplin dan mengutamakan pelayanan yang terbaik kepada para pelanggan.
\end{abstract}

Kata kunci: kualitas, kepuasan, kinerja, tingkat, kepentingan 


\section{PENDAHULUAN}

Tingkat pelayanan yang baik dalam perusahaan akan memberi nilai plus, dan sangat berpengaruh terhadap kepuasan pelanggan, tidak hanya pada perusahaan manufaktur namun juga pada perusahaan jasa, salah satunya Stasiun Kereta Api Klaten. Stasiun Klaten yang berkode (KT) ini terletak di Tonggalan, Klaten Tengah, Kota Klaten, Provinsi Jawa Tengah, Indonesia dan berada pada Daerah Operasi VI Yogyakarta.

Diketahui hasil perhitungan tingkat kualitas kepuasan berdasarkan perhitungan Service Performance dengan tingkat kesesuaian antara 44,54\% - 77,45\%, Costumer Satisfaction Index dengan nilai sebesar $61,60 \%$ yang berarti tingkat pelayanan yang diberikan Stasiun Klaten terhadap penumpang tergolong dalam kriteria very poor yaitu sangat buruk. Dan hasil perhitungan Importance Performance Analysis terdapat 5 atribut kualitas pelayanan yang termasuk kedalam kuadran prioritas utama yaitu atribut kualitas nomor 6 , atribut kualitas nomor 7 , atribut kualitas nomor 12, atribut kualitas nomor 20 dan atribut kualitas nomor 21.

Oleh karena itu, dalam penelitian ini dilakukan untuk menganalisis dan evaluasi kualitas pelayanan Stasiun Klaten dengan mengajukan kuesioner pertanyaan tentang pelayanan di Stasiun Klaten untuk dijadikan bahan perbaikan di masa yang akan datang. Seperti yang dilakukan oleh Penelitian terkait yang pernah dilakukan antara lain, Surya (2018) dan Setyaningsih (2013) yang menganalisis tentang kualitas pelayanan dengan menggunakan kuesioner dan metode Servperf, IPA, dan CSI, dengan hasil memberikan usulan perbaikan kualitas pada 8 dan 15 atribut pelayanan yang memiliki tingkat kepentingan tinggi dan kinerja pelayanan yang rendah. Berbeda dengan penelitian yang dilakukan oleh Herbasuki dkk, (2016) dan Herni (2017) yang menganalisis kepuasan konsumen dengan menggunakan kuesioner namun tidak memberikan usulan perbaikan berdasarkan atribut-atribut yang ada.

\section{Landasan Teori Kualitas Jasa}

Menurut Rachmansyah

(2013)
Pelayanan adalah setiap tindakan atau kegiatan yang dapat ditawarkan oleh suatu pihak kepada pihak lain. Pelayanan merupakan perilaku produsen dalam rangka memenuhi kebutuhan dan keinginan pelanggan demi tercapainya kepuasan pelanggan.

\section{Kepuasan Pelanggan}

Menurut Devani dan Rizko (2016). Kepuasan pelanggan adalah hasil (outcome) yang dirasakan atas penggunaproduk atau jasa, sama atau melebihi harapan yang diinginkan. Terdapat beberapa faktor yang mempengaruhi kepuasan pelanggan antara lain: biaya, harga, emosi, kualitas pelayanan dan kualitas produk.

\section{Penentuan Jumlah Sempel}

Banyaknya pelanggan yang menjadi pasien di rumah sakit dapat menghambat survey secara keseluruhan karena keterbatasan waktu. Oleh karena itu dibutuhkan sampel yang dapat mewakili semua populasi pelanggan rumah sakit. Cara menentukan jumlah sampel menggunakan Rumus Slovin.

\section{Uji Validitas Dan Uji Reliabilitas}

Uji validitas dilakukan dengan tujuan sebagai petunjuk sejauh mana suatu alat pengukur (instrumen) mengukur apa yang ingin diukur, sedangkan uji reliabilitas digunakan untuk mengetahui apakah hasil pengukuran tersebut dapat dipercaya untuk digunakan dalam pengumpulan data atau tidak (Sugiyono, 2005)

\section{Service Performance}

Service Performance adalah kinerja dari pelayanan yang diterima oleh konsumen itu sendiri dan menilai kualitas dari pelayanan yang benar-benar mereka rasakan. Berbeda dengan metode Servqual, Servperf memiliki keunggulan dalam memberikan informasi atribut kualitas pelayanan manakah yang lebih penting untuk diperbaiki sehingga anatara keinginan dan kepentingan dapat menjadi lebih tampak dalam analisa atribut kualitas layanan (Efranto, dkk., 2008). 


\section{Customers Satisfaction Index (CSI)}

Menurut Hidayati dan Prasetyo (2015) Customer Satisfaction Index (CSI) digunakan untuk mengetahui tingkat kepuasan pengunjung secara menyeluruh dengan melihat tingkat kepentingan dari atribut-atribut produk/jasa. Menurut Aritonang (2005) untuk mengetahui besarnya CSI langkah-langkah sebagai berikut: Besarnya CSI dapat diketahui dengan langkah- langkah sebagai berikut (Aritonang, 2005):

1. Menentukan Mean Importance Score(MIS)

2. Membuat Weight Factors (WF) per atribut

3. Menentukan Mean Satisfaction Score (MSS) tiap atribut

4. Membuat Weight Score (WSi)

5. Menghitung Customer Satisfaction Index (CSI)

\section{Importance Performance Analysis (IPA)}

Menurut Prajogo dan Peggy (2001) penggunaan metode Importance Performance Analysis adalah dalam mengukur tingkat kepuasan pelayanan jasa yang masuk pada kuadran-kuadran pada peta Importance Performance Matrix. Dalam metode ini diperlukan pengukuran tingkat kesesuaian untuk mengetahui seberapa besar pelanggan merasa puas terhadap kinerja perusahaan, dan seberapa besar pihak penyedia jasa memahami apa yang diinginkan pelanggan terhadap jasa yang mereka berikan. Dengan caramembuat peta posisi importance performance yang merupakan suatu bangun yang dibagi menjadi empat kuardan yang dibatasi oleh dua buah garis berpotongan tegak lurus pada titik-titik sebagai berikut (Tjiptono, 2000).

\section{Teoriya Resheniya Izobreatatelskikh Zadatch (TRIZ)}

TRIZ merupakan singkatan dari Bahasa Rusia Teoriya Resheniya Izobreatatelskikh Zadatch yang dikembangkan oleh G.S Altshuller dan rekannya dari Uni Soviet. TRIZ sebuah filosofi teknologi, metode ilmu dan teknologi, cara berpikir yang sistematis untuk ide pengembangan yang kreatif, sistem yang mencakup teknologi pengetahuan, software untuk basis data, dan lain-lain. Singkatnya menyediakan prinsipprinsip yang hebat dan alat yang konkrit untuk pemikiran kreatif dalam rangkaian teknologi (Barry, 2006). Langkah aplikasi TRIZ dalam bidang jasa untuk mencapai inovasi sistematis melalui pemecahan masalah yang inovatif, modifikasi TRIZ dalam desain jasa (Zhang et. al., 2003).

\section{METODE PENELITIAN}

Dalam penelitian ini, dilakukan penelitian yang berfokus pada kualitas pelayanan terhadap kepuasan pelanggan. Untuk mempermudahkan dalam melakukan penelitian maka dalam pelaksanaannya penelitian dibagi menjadi beberapa tahapan sebagai berikut:

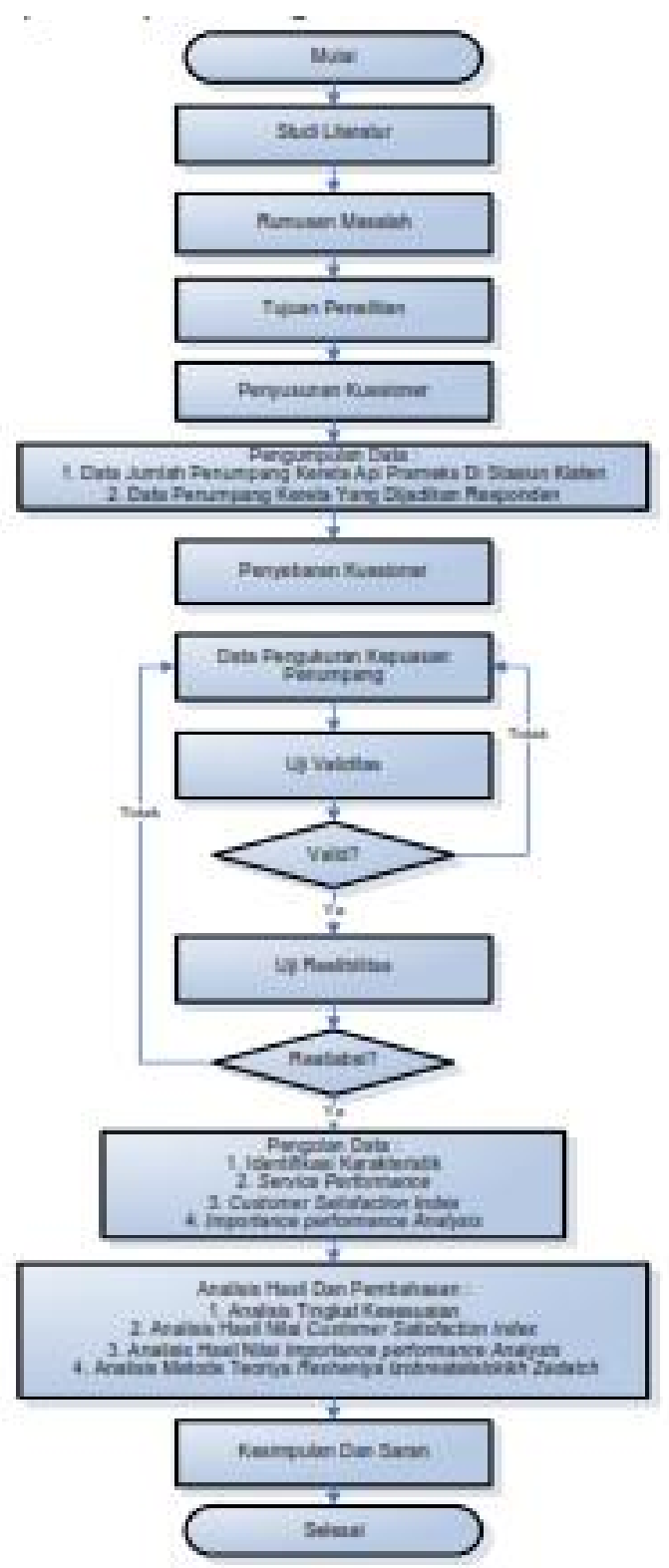

Gambar 1. Diagram Penelitian 
Berikut merupakan uraian metode penelitian di atas:

1. Studi literatur

Studi literatur merupakan referensi atau sebagai acuan dalam penulisan laporan penelitian ini untuk memperlajari tentang metode Service Performance, Customer Satisfaction Index, Importance Performance Analysis, dan Teoriya Resheniya Izobreatatelskikh Zadatch Referensi berupa buku, e-book dan jurnal penelitian terdahulu sebagai referensi dalam penulisan laporan.

2. Identifikasi Masalah

Identifikasi masalah dalam penelitian ini dilakukan dengan cara melakukan wawancara pihak Stasiun Klaten mengenai jumlah penumpang kereta api tiap harinya dalam periode satu tahun dan mengamati secara langsung keadaan di lingkungan Stasiun kemudian hasil pengolan data dengan metode Service Performance, Customer Satisfaction Index, Importance Performance Analysis digunakan sebagai latar belakang masalah.

3. Rumusan Masalah

Rumusan masalah ditentukan sesuai dengan permasalahan yang ada di Stasiun Klaten sesuai dengan yang digambarkan pada latar belakang penelitian ini yaitu tingkat kepuasan penumpang yang rendah.

4. Tujuan Penelitian

Tujuan penelitian ini yaitu mengukur tingkat kualitas pelayanan yang ada di Stasiun Klaten dan selanjutnya dilakukan usulan perbaikan berdasarkan atribut yang perlu diperbaiki.

5. Penyebaran Kuesioner

Kuesioner digunakan sebagai alat bantu untuk memudahkan dalam pengambilan data tentang kualitas pelayanan terhadap kepuasan penumpang kereta api di Stasiun Klaten. Kuesioner akan disebarkan kepada para penumpang pada KA Prameks, hal ini dikarenakan KA Prameks paling banyak penumpangnya dan beroperasi setiap hari.

6. Pengumpulan data

Pengumplan data dilakukan dengan cara melakukan observasi langsung ke Stasiun Klaten langsung untuk mengetahui kondisi Stasiun yang sebenarnya. Data yang dikumpulkan antara lain: a. Data jumlah penumpang dan identitas yang dijadikan sebagai responden sebanyak 25 orang. (Lampiran 2)

b. Kuesioner pengukuran kepuasan penumpang digunakan untuk mendapatkan hasil penilaian para penumpang kereta api pada pelayanan yang diberikan pihak Stasiun Klaten. (Lampiran 3)

7. Pengolahan Data

Pada tahap pengolahan data ini kuisioner yang telah terkumpul kemudian akan diolah dengan cara sebagai berikut:

a. Uji Validitas

Uji validias dilakukan untuk mengukur kevalidan dari data kuesioner yang telah di isi oleh responden berdasarkan atribut kualitas pelayanan di Stasiun Klaten. Yaitu uji validitas kinerja dan uji validitas harapan.

b. Uji Reliabilitas

Uji reliabilitas dilakuakan untuk mengetahui bahwa data yang diukur dari kuesioner yang digunakan itu konsisten atau tidak. Uji reliabilitas meliputi uji realibilitas kinerja dan uji realiabilitas harapan.

c. Mengukur rata-rata tingkat kepentingan dan kepuasan pada Service Performance. Perhitungan Service Performance dilakukan untuk mengukur tingkat kesesuaian masing-masing atribut kualitas pelayanan yang telah diberikan oleh Stasiun Klaten dengan kualitas pelayanan yang diharapkan penumpang.

d. Perhitungan nilai Customer Satisfaction Index, pengukuran Customer Satisfaction Index Digunakan untuk mengetahui tingkat kepuasan penumpang secara menyeluruh dengan melihat tingkat kepentingan dari atributatribut kualitas. Hasil pengolan data dengan metode ini digunakan sebagai latar belakang masalah.

e. Pembuatan grafik Importance Performance Analysis Digunakan untuk mengetahui atribut mana yang harus diperbaiki yang dihasilkan dari perhitungan dan diagram kartesius. Diagram kartesius terbagi menjadi empat kuadran yang terdiri dari dua 
sumbu yang saling berpotongan yaitu sumbu $X$ dan sumbu $Y$. Sumbu $X$ yang berarti kepuasan konsumen sedangkan sumbu $Y$ yang berarti tingkat kepentingan. Hasil pengolahan data dengan metode ini digunakan sebagai latar belakang masalah.

f. Teoriya Resheniya Izobreatatelskikh Zadatch metode ilmu dan teknologi, cara berpikir yang sistematis untuk ide pengembangan yang kreatif, sistem yang mencakup teknologi pengetahuan, software untuk basis data, dan lain-lain. Singkatnya menyediakan prinsip-prinsip yang hebat dan alat yang konkrit untuk pemikiran kreatif dalam rangkaian teknologi

8. Analisis Hasil dan Pembahasan

Analisis hasil dan pembahasan dilakukan untuk menganalisa dan membahas hasil dari analisis dan perhitungan tingkat kepuasan pelanggan dengan menggunakan metode Service Performance, Customer Satisfaction Index, Importance Performance Analysis dan TRIZ

9. Kesimpulan dan Saran

a. Kesimpulan

Dilakukan untuk menarik sebuah kesimpulan berdasarkan hasil dari penelitian yang telah dilakukan.

b. Saran

Dilakukan untuk memberikan masukan kepada pihak Stasiun Klaten untuk lebih baik lagi dalam meningkatkan pelayanan kepada penumpang kereta api.

\section{HASIL DAN PEMBAHASAN}

Data responden yang telah dikumpulkan kemudian dilakukan pengolahan data selanjutnya. Pengolahan data selanjutnya dapat di lihat sebagai berikut:

\section{Uji Validitas}

Setelah data atribut kualitas pelayanan diuji berdasarkan nilai $\mathrm{N}=26$ dan nilai signifikan two-tailed 0,05 sehingga didapatkan nilai tabel-r dengan df $24(26-2=24)$ sebesar 0,3882 . Uji validitas terbagi menjadi dua yaitu:

\section{Validitas Kenyataan}

Tabel 1. Validitas Kenyataan

\begin{tabular}{|l|l|l|l|}
\hline Nomor & R-Hitung & R-Tabel & keterangan \\
\hline 1 & 0,6884 & 0,3882 & VALID \\
\hline 2 & 0,5594 & 0,3882 & VALID \\
\hline 3 & 0,5667 & 0,3882 & VALID \\
\hline 4 & 0,5417 & 0,3882 & VALID \\
\hline 5 & 0,7088 & 0,3882 & VALID \\
\hline 6 & 0,4591 & 0,3882 & VALID \\
\hline 7 & 0,4290 & 0,3882 & VALID \\
\hline 8 & 0,4728 & 0,3882 & VALID \\
\hline 9 & 0,5698 & 0,3882 & VALID \\
\hline 10 & 0,5731 & 0,3882 & VALID \\
\hline 11 & 0,4148 & 0,3882 & VALID \\
\hline 12 & 0,4404 & 0,3882 & VALID \\
\hline 13 & 0,6111 & 0,3882 & VALID \\
\hline 14 & 0,5122 & 0,3882 & VALID \\
\hline 15 & 0,4210 & 0,3882 & VALID \\
\hline 16 & 0,4625 & 0,3882 & VALID \\
\hline 17 & 0,6920 & 0,3882 & VALID \\
\hline 18 & 0,6299 & 0,3882 & VALID \\
\hline 19 & 0,4588 & 0,3882 & VALID \\
\hline 20 & 0,5634 & 0,3882 & VALID \\
\hline 21 & 0,5400 & 0,3882 & VALID \\
\hline 22 & 0,4920 & 0,3882 & VALID \\
\hline 23 & 0,5704 & 0,3882 & VALID \\
\hline 24 & 0,4775 & 0,3882 & VALID \\
\hline 25 & 0,4315 & 0,3882 & VALID \\
\hline 26 & 0,7463 & 0,3882 & VALID \\
\hline $547 b e r$ & $P e n g 01 a n a n$ & $D a t a, 219$ & \\
\hline
\end{tabular}

(Sumber: Pengolahan Data, 2019)

\section{Variabel Harapan}

Tabel 2. Validitas Harapan

\begin{tabular}{|l|l|l|l|}
\hline Nomor & R-Hitung & R-Tabel & keterangan \\
\hline 1 & 0,4526 & 0,3882 & VALID \\
\hline 2 & 0,5989 & 0,3882 & VALID \\
\hline 3 & 0,5656 & 0,3882 & VALID \\
\hline 4 & 0,4760 & 0,3882 & VALID \\
\hline 5 & 0,4788 & 0,3882 & VALID \\
\hline 6 & 0,4657 & 0,3882 & VALID \\
\hline 7 & 0,5247 & 0,3882 & VALID \\
\hline 8 & 0,5719 & 0,3882 & VALID \\
\hline 9 & 0,5022 & 0,3882 & VALID \\
\hline 10 & 0,4707 & 0,3882 & VALID \\
\hline 11 & 0,5570 & 0,3882 & VALID \\
\hline 12 & 0,4648 & 0,3882 & VALID \\
\hline 13 & 0,4896 & 0,3882 & VALID \\
\hline 14 & 0,4378 & 0,3882 & VALID \\
\hline 15 & 0,5744 & 0,3882 & VALID \\
\hline
\end{tabular}




\begin{tabular}{|l|l|l|l|}
\hline 16 & 0,5761 & 0,3882 & VALID \\
\hline 17 & 0,5455 & 0,3882 & VALID \\
\hline 18 & 0,4535 & 0,3882 & VALID \\
\hline 19 & 0,4963 & 0,3882 & VALID \\
\hline 20 & 0,4402 & 0,3882 & VALID \\
\hline 21 & 0,4799 & 0,3882 & VALID \\
\hline 22 & 0,3929 & 0,3882 & VALID \\
\hline 23 & 0,5525 & 0,3882 & VALID \\
\hline 24 & 0,4260 & 0,3882 & VALID \\
\hline 25 & 0,4301 & 0,3882 & VALID \\
\hline 26 & 0,5503 & 0,3882 & VALID \\
\hline
\end{tabular}

(Sumber: Pengolahan Data, 2019)

\section{Uji Reliabilitas}

Setelah diuji validitas selanjutnya perlu dilakukan uji reliabilitas untuk menguji konsistensi alat ukur apakah hasil uji tetap konsisten jika dilakukan pengukuran ulang. Tingkat reliabilitas diuji dengan menggunakan metode alpha cronbach diukur berdasarkan nilai alpha 0 sampai dengan 1 . Tingkat reliabilitas suatu pengukur dapat digolongkan menjadi lima, berikut penggolongan tingkat reliabilitas ditunjukan pada Tabel 3

Tabel 3. Validitas Harapan

\begin{tabular}{|c|c|}
\hline Nilai & Keterangan \\
\hline $0-0,200$ & Kurang Reliabel \\
\hline $0,201-0,400$ & Agak Reliabel \\
\hline $0,401-0,600$ & Cukup Reliabel \\
\hline $0,601-0,800$ & Reliabel \\
\hline $0,801-1$ & Sangat Reliabel \\
\hline
\end{tabular}

(Sumber: Janti, 2014)

1. Reliabilitas Kenyataan

Tabel 4. Reliabilitas Kenyataan

\begin{tabular}{|c|r|r|}
\hline \multicolumn{3}{|c|}{ Reliability Statistics } \\
\hline $\begin{array}{c}\text { Cronbach's } \\
\text { Alpha }\end{array}$ & $\begin{array}{c}\text { Cronbach's Alpha } \\
\text { Based on } \\
\text { Standardized Items }\end{array}$ & $\begin{array}{c}\text { N of } \\
\text { Items }\end{array}$ \\
\hline .731 & .874 & 27 \\
\hline
\end{tabular}

(Sumber: Pengolahan Data, 2019)
2. Reliabilitas Harapan

Tabel 5. Reliabilitas Harapan

\begin{tabular}{|r|r|r|}
\hline \multicolumn{3}{|c|}{ Reliability Statistics } \\
\hline $\begin{array}{c}\text { Cronbach's } \\
\text { Alpha }\end{array}$ & $\begin{array}{c}\text { Cronbach's Alpha } \\
\text { Based on } \\
\text { Standardized Items }\end{array}$ & $\begin{array}{c}\text { N of } \\
\text { Items }\end{array}$ \\
\hline .735 & .886 & 27 \\
\hline
\end{tabular}

(Sumber: Pengolahan Data, 2019)

\section{Service Performance}

Perhitungan service performance dilakukan untuk mengukur tingkat kesesuaian masing-masing atribut kualitas pelayanan pada kenyataan yang ada di Stasiun Klaten dengan kulitas pelayanan yang diharapkan pasien (responden). Perhitungan Service Performance dapat dilihat pada Tabel 6.

Tabel 6. Tingkat Kesesuaian Atribut Kualitas

\begin{tabular}{|l|l|l|l|}
\hline $\begin{array}{l}\text { Nomor } \\
\text { Atribut }\end{array}$ & $\begin{array}{c}\text { Rata-rata } \\
\text { Kenyataan }\end{array}$ & $\begin{array}{c}\text { Rata-rata } \\
\text { tingkat } \\
\text { Harapan }\end{array}$ & $\begin{array}{c}\text { tingkat } \\
\text { kesesuaian }\end{array}$ \\
\hline 1 & 3,84 & 4,72 & $81,35 \%$ \\
\hline 2 & 4 & 4,6 & $86,95 \%$ \\
\hline 3 & 3,96 & 4,68 & $84,61 \%$ \\
\hline 4 & 3,76 & 4,8 & $78,33 \%$ \\
\hline 5 & 3,68 & 4,68 & $78,63 \%$ \\
\hline 6 & 3,68 & 4,76 & $77,31 \%$ \\
\hline 7 & 3,76 & 4,6 & $81,73 \%$ \\
\hline 8 & 3,64 & 4,72 & $77,11 \%$ \\
\hline 9 & 3,8 & 4,72 & $80,50 \%$ \\
\hline 10 & 3,8 & 4,68 & $81,19 \%$ \\
\hline 11 & 3,68 & 4,64 & $79,31 \%$ \\
\hline 12 & 3,88 & 4,8 & $80,83 \%$ \\
\hline 13 & 3,72 & 4,68 & $79,48 \%$ \\
\hline 14 & 3,56 & 4,72 & $75,42 \%$ \\
\hline 15 & 3,64 & 4,56 & $79,82 \%$ \\
\hline 16 & 3,88 & 4,68 & $82,90 \%$ \\
\hline 17 & 3,76 & 4,64 & $81,03 \%$ \\
\hline 18 & 3,44 & 4,68 & $74,13 \%$ \\
\hline 19 & 3,88 & 4,52 & $85,84 \%$ \\
\hline 20 & 3,92 & 4,52 & $87,72 \%$ \\
\hline Total & 75,28 & 93,4 & $1614,19 \%$ \\
\hline
\end{tabular}

(Sumber: Pengolahan Data, 2019)

\section{Customers Satisfaction Index (CSI)}

Pengukuran CSI digunakan untuk mengetahui tingkat kepuasan penumpang secara menyeluruh dengan melihat tingkat 
kepentingan dari atribut-atribut kualitas. Perhitungan CSI dapat dilihat pada Tabel 7

Tabel 7. Rekapitual Hasil Perhitungan Customer Satisfaction Index (CSI)

\begin{tabular}{|l|l|l|l|l|}
\hline No & $($ MIS $)$ & $\begin{array}{c}\text { (WF)(MIS/T } \\
\text { otal MIS) }\end{array}$ & (MSS) & $\begin{array}{c}\text { (WSi)( } \\
\text { WF } x \\
\text { MSS) }\end{array}$ \\
\hline 1 & 4,24 & 0,038 & 2,76 & 0,104 \\
\hline 2 & 4,28 & 0,039 & 2,92 & 0,130 \\
\hline 3 & 4,2 & 0,038 & 2,92 & 0,110 \\
\hline 4 & 4,08 & 0,036 & 3,16 & 0,113 \\
\hline 5 & 4,4 & 0,039 & 2,68 & 0,138 \\
\hline 6 & 4,4 & 0,039 & 1,96 & 0,127 \\
\hline 7 & 4,64 & 0,041 & 2,32 & 0,109 \\
\hline 8 & 4,48 & 0,040 & 2,6 & 0,107 \\
\hline 9 & 4,36 & 0,039 & 2,96 & 0,131 \\
\hline 10 & 4,64 & 0,041 & 2,8 & 0,180 \\
\hline 11 & 4,24 & 0,037 & 2,52 & 0,106 \\
\hline 12 & 4,56 & 0,040 & 2,2 & 0,099 \\
\hline 13 & 4,08 & 0,036 & 2,6 & 0,092 \\
\hline 14 & 4,04 & 0,035 & 2,2 & 0,121 \\
\hline 15 & 4 & 0,034 & 2,56 & 0,092 \\
\hline 16 & 4,4 & 0,039 & 2,8 & 0,107 \\
\hline 17 & 4,28 & 0,038 & 2,88 & 0,142 \\
\hline 18 & 4,28 & 0,038 & 2,76 & 0,118 \\
\hline 19 & 4,24 & 0,037 & 2,92 & 0,115 \\
\hline 20 & 4,28 & 0,038 & 2,36 & 0,126 \\
\hline 21 & 4,24 & 0,037 & 2,48 & 0,113 \\
\hline 22 & 4,28 & 0,038 & 2,84 & 0,110 \\
\hline 23 & 4 & 0,037 & 2,92 & 0,119 \\
\hline 24 & 3,92 & 0,035 & 2,92 & 0,102 \\
\hline 25 & 4,08 & 0,038 & 2,56 & 0,121 \\
\hline 26 & 4,24 & 0,037 & 2,88 & 0,148 \\
\hline Total & 110,88 & 0,9840 & 66,6 & 3,080 \\
\hline $54 m 5$ & Penng & \\
\hline
\end{tabular}

(Sumber: Pengolahan Data, 2019

\section{Importance Performance Analysis}

Importance Performance Analysis digunakan untuk mengukur tingkat kualitas pelayanan yang sudah diberikan dan selanjutnya membandingkannya dengan tingkat harapan konsumen. Dari hasil perhitungan yang sudah dilakukan selanjutnya adalah membuat diagram kartesius. Diagram kartesius terbagi menjadi empat kuadran yang terdiri dari dua sumbu yang saling berpotongan yaitu sumbu $X$ dan sumbu $Y$. Sumbu $X$ yang berarti kepuasan konsumen sedangkan sumbu $Y$ yang berarti tingka kepentingan. Hasil perhitungan
Importance Performance Analysis

berdasarkan ditunjukan pada Tabel 8

Tabel 8. Rekapitulasi Hasil Perhitungan Importance Performance Analysis

\begin{tabular}{|c|c|c|}
\hline $\begin{array}{l}\text { Nomor } \\
\text { Atribut }\end{array}$ & $\begin{array}{r}\text { Rata-rata } \\
\text { Kenyataan }\end{array}$ & $\begin{array}{l}\text { Rata-rata } \\
\text { tingkat } \\
\text { harapan }\end{array}$ \\
\hline 1 & 2,76 & 4,24 \\
\hline 2 & 2,92 & 4,28 \\
\hline 3 & 2,92 & 4,2 \\
\hline 4 & 3,16 & 4,08 \\
\hline 5 & 2,68 & 4,4 \\
\hline 6 & 1,96 & 4,4 \\
\hline 7 & 2,32 & 4,64 \\
\hline 8 & 2,6 & 4,48 \\
\hline 9 & 2,96 & 4,36 \\
\hline 10 & 2,8 & 4,64 \\
\hline 11 & 2,52 & 4,24 \\
\hline 12 & 2,2 & 4,56 \\
\hline 13 & 2,6 & 4,08 \\
\hline 14 & 2,2 & 4,04 \\
\hline 15 & 2,56 & 4 \\
\hline 16 & 2,8 & 4,4 \\
\hline 17 & 2,88 & 4,28 \\
\hline 18 & 2,76 & 4,28 \\
\hline 19 & 2,92 & 4,24 \\
\hline 20 & 2,36 & 4,28 \\
\hline 21 & 2,48 & 4,24 \\
\hline 22 & 2,84 & 4,28 \\
\hline 23 & 2,92 & 4 \\
\hline 24 & 2,92 & 3,92 \\
\hline 25 & 2,56 & 4,08 \\
\hline 26 & 2,88 & 4,24 \\
\hline Total & 66,6 & 110,88 \\
\hline
\end{tabular}

(Sumber: Pengolahan Data, 2019)

Berdasarkan Tabel 8 didapatkan jumlah hasil rata-tara kenyataan sebesar 66,6 dan jumlah rata-rata harapan sebesar 110,88. Langkah selanjutnya adalah menentukan sumbu $X$ dan sumbu $Y$. Sumbu $X$ dan sumbu $Y$ yang nanti digunakan untuk membuat garis perpotongan pada diagram kartesius yang terbagi menjadi empat kuadran. Gambar diagram kartesius dapat dilihat di Gambar 2 


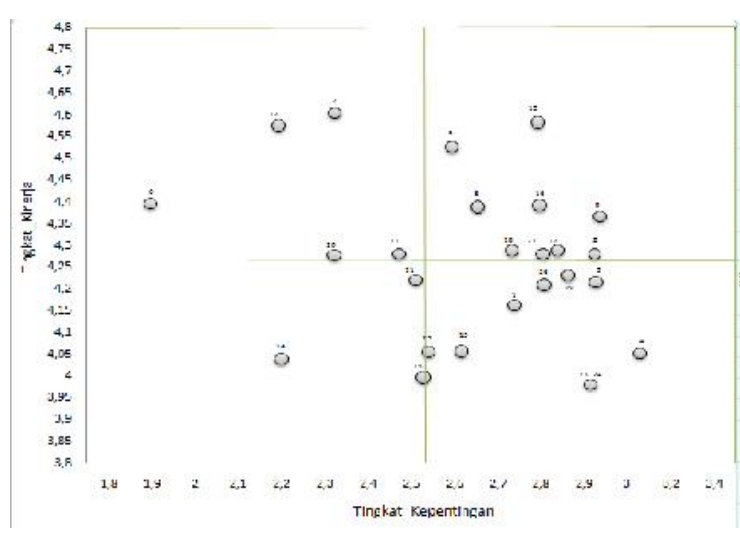

Gambar 2. Diagram kartesius

(Sumber: Pengolahan Data, 2019)

\section{Pembahasan}

\section{Analisis Tingkat Kesesuaian}

1. Analisis Service Performance

Sesuai dengan hasil perhitungan menggunakan metode service performance untuk tingkat kesesuaian atribut kualitas pelayanan di Stasiun Klaten memiliki rata-rata sebesar $62,66 \%$ dan didapatkan nilai kesesuaian atribut kualitas pelayanan Stasiun Klaten terendah sebesar $44,54 \%$ pada dimensi reliability (kendalan) yaitu pada atribut pelayanan tiket cepat, hal ini disebabkan karena pelayanan tiket kurang cepat dan menyebabkan antrian yang sangat panjang. Sedangkan nilai tertinggi kesesuaian atribut kualitas pelayanan sebesar $77,45 \%$ pada dimensi reliability (kendalan) yaitu pada atribut ketersediaan informasi terkait dengan jadwal Kereta Api. Dari hasil tersebut artinya kualitas pelayanan yang ada di Stasiun Klaten belum $80 \%$ atau belum memuaskan sesuai yang diharapkan penumpang. Sehingga Stasiun Klaten perlu melakukan peningkatan kualitas pelayanannya.

2. Analisis Customer Satisfaction Index (CSI) dalam perhitungan Customer

$$
\text { Satisfaction Index (CSI) tentang }
$$

kualitas pelayanan di Stasiun Klaten didapatkan nilai kepuasan penumpang yaitu sebesar $61,60 \%$. Nilai index kepuasan penumpang $61,60 \%$ tergolong dalam range $\leq$ $64 \%$, dengan ini pelayanan yang ada di Stasiun Klaten dapat dikatakan sangat buruk (Very Poor) sehingga kualitas pelayanan yang ada di Stasiun Klaten diadakan perbaikan.

\section{Importance Performnace Analysis (IPA)}

Berdasarkan hasil perhitungan Importance Performance Analysis dan pembuatan diagram kartesius menggunakan software SPSS 16.0 for Windows didapatkan atribut kualitas pelayanan yang menjadi prioritas utama dalam meningkatkan kualitas pelayanan di Stasiun Klaten yaitu sebanyak 5 atribut kualitas pelayanan. Dengan uraian sebagai berikut :

a. Atribut kualitas nomor 6 dimensi reliability (kendalan), yaitu pada atribut pelayanan tiket cepat. Dengan nilai tingkat kesesuaian atribut kualitas sebesar $44,45 \%$.

b. Atribut kualitas nomor 7 dimensi reliability (kendalan), yaitu pada atribut Mesin tiket selalu dalam konsisi baik tidak error. Dengan nilai tingkat kesesuaian atribut kualitas sebesar

c. Atribut kualitas nomor 12 dimensi Tangibles(bukti fisik), yaitu pada atribut Kursi bagi calon penumpang dan pengantar memadai. Dengan nilai tingkat kesesuaian atribut kualitas sebesar $48,24 \%$.

d. Atribut kualitas nomor 20 dimensi Tangibles (bukti fisik), yaitu pada atribut Fasilitas penunjang pelayanan lengkap dan memadai (ruang tunggu, kipas angin, toilet, mushola, kantin). Dengan nilai tingkat kesesuaian atribut kualitas sebesar $55,14 \%$.

e. Atribut kualitas nomor 21 dimensi Responsivenes (DayaTanggap), yaitu pada atribut Kecepatan dalam merespon keluhan dan permasalahan pelanggan. Dengan nilai tingkat kesesuaian atribut kualitas sebesar $58,19 \%$.

\section{Usulan Perbaikan Dengan Metode TRIZ}

Dari 4 atribut kualitas yang menjadi prioritas utama peningkatan kualitas pelayanan diperlukan usulan atau solusi dengan menggunakan metode TRIZ. Berikut adalah sistematika atau langkah aplikasi TRIZ:

1. Problem Identification

Identifikasi masalah dilakukan dengan menganalisis dari beberapa metode yang sudah dilakukan pada tahapan- 
tahapan sebelumya servperf, CSI dan IPA.

2. Preliminary Problem Analysis

Menangani masalah awal dengan menganalisis satu persatu metode mulai dari servperf, CSI, IPA, sehingga didapatkan 5 atribut kualitas yang diprioritaskan dan perlu dilakukan perbaikan.

3. Problem Modelling and Formulation

Berikut adalah pemodelan dari ke enam atribut kualitas yang menjadi prioritas utama dengan hasil sebagai berikut:

a. Pelayanan tiket cepat (A6) masuk dalam pemodelan parameter nomor 27 yaitu kecepatan (speed). Pelayanan tiket cepat sangat berpengaruh terhadap kepuasan pelanggan karena apabila pelayanan tiket cepat tidak akan menyebabkan antrian panjang.

b. Mesin tiket selalu dalam konsisi baik tidak error (A7) masuk dalam parameter nomor 36 yaitu kehandalan (Reliability). Mesin tiket selalu dalam konsisi baik tidak errorsangat penting untuk kepuasan pelanggan karena dengan adanya mesin tiket pelanggan tidak harus antri panjang di loket tiket.

c. Kursi bagi calon penumpang dan pengantar memadai (A12) masuk dalam parameter nomor 8 yaitu volume objek tak bergerak (volume of stationary object). Kursi untuk calon penumpang dan pengantar sangat berpengaruh terhadap tingkat kepuasan penumpang dan pengantar, karena dengan adanya kursi yang memadai pelanggan tidak harus berdiri menunggu kedatangan kereta.

d. Fasilitas penunjang pelayanan lengkap dan memadai (ruang tunggu, kipas angin, toilet, mushola, kantin) (A20) masuk dalam parameter nomor 39 yaitu produktivitas (productivity) berupa Fasilitas penunjang pelayanan lengkap dan memadai (ruang tunggu, kipas angin, toilet, mushola, kantin) memberikan rasa nyaman pada penumpang dan meningkatkan kepuasan penumpang. e. Kecepatan dalam merespon keluhan dan permasalahan pelanggan (A21) masuk dalam parameter nomor 36 yaitu kehandalan (Reliability). Kecepatan dalam merespon keluhan dan permasalahan pelanggan bisa membuat pelanggan puas dengan pelayanan yang cepat dan tanggapan yang baik.

4. Contradiction Analysis

Setelah dilakukannya pemodelan dari tahap premilinary problem analysis dilanjutkan dengan menganalisis kontradiksi masalah. Kontradiksi sendiri terbagi menjadi 2 yaitu kontradiksi teknis (kontradiksi yang membahas mengenai proses dari suatu sistem) dan kontradiksi fisik (kontradiksi yang membahas tentang bentuk suatu elemen dari sistem.

5. Contradiction Elimination

Setelah menganalisis kontradiksi masalah dilanjutkan eleminasi kontradiksi atau penyisihan. Berikut eleminasi kontradiksi.

Tabel 9. Contradiction Elimination

\begin{tabular}{|c|c|}
\hline Kontradiksi & Atribut Kualitas \\
\hline & 1. Atribut kualitas nomor \\
& 6 (Pelayanan tiket \\
& cepat) \\
& 2. Atribut kulitas nomor \\
& 7 (Mesin tiket selalu \\
& dalam konsisi baik tidak \\
& error) \\
& 3. Atribut kualitas nomor \\
& 12 (Kursi bagi calon \\
Kontradiksi & penumpang dan \\
Teknis & pengantar memadai) \\
& 4. Atribut kualitas nomor \\
& 20 (Fasilitas penunjang \\
& pelayanan lengkap \\
& dan memadai (ruang \\
& tunggu, kipas angin, \\
& toilet, mushola, kantin)) \\
& 5. Atribut kualitas nomor \\
& 21 (Kecepatan dalam \\
& merespon keluhan dan \\
& permasalahan \\
& pelanggan) \\
\hline
\end{tabular}

(Sumber: Pengolahan Data, 2019)

6. Solution Evaluation

Setelah dilakukan identifikasi masalah 
hingga eleminasi kontradiksi masalah kemudian dilakukannya evaluasi solusi dan seleksi solusi (solution selection) yang terbaik untuk masalah yang dihadapi. Adapun evaluasi solusi dan seleksi solusi sebagai berikut:

Tabel 10. Solution Evaluation dan Solution Selection

\begin{tabular}{|c|c|}
\hline Atribut & Usulan Perbaikan \\
\hline $\begin{array}{l}\text { Pelayanan } \\
\text { tiket cepat }\end{array}$ & $\begin{array}{l}\text { Menambah mesin tiket agar } \\
\text { petugas pelayanan di loket tiket } \\
\text { tidak antri terlalu panjang dan } \\
\text { memberi nomer antrian agar } \\
\text { tidak berdesak-desakan saat } \\
\text { antri di loket tiket. }\end{array}$ \\
\hline $\begin{array}{l}\text { Mesin tiket } \\
\text { tidak error }\end{array}$ & $\begin{array}{l}\text { Perawatan rutin mesin tiket dan } \\
\text { selalu dalam pengawasan } \\
\text { penjaga tiket agar bisa } \\
\text { memandu calon penumpang } \\
\text { yang membeli tiket. Bila mesin } \\
\text { tiket lancar antrian di loket tiket } \\
\text { juga lancar. }\end{array}$ \\
\hline $\begin{array}{l}\text { Kursi } \\
\text { penumpang } \\
\text { dan } \\
\text { pengantar }\end{array}$ & $\begin{array}{l}\text { Menambah jumlah kursi diruang } \\
\text { antrian tiket dan antrian } \\
\text { penumpang untuk menjaga } \\
\text { kenyamanan bagi para calon } \\
\text { penumpang dan pengantar, } \\
\text { karena dengan adanya kursi } \\
\text { yang memadai pelanggan tidak } \\
\text { harus berdiri menunggu } \\
\text { kedatangan kereta }\end{array}$ \\
\hline $\begin{array}{l}\text { Fasilitas } \\
\text { penunjang }\end{array}$ & $\begin{array}{l}\text { Menambah fasilitas untuk } \\
\text { kepuasan dan kenyamanan } \\
\text { pelanggan seperti menambah } \\
\text { kursi diruang antrian tiket dan } \\
\text { ruang tunggu, memperbaiki } \\
\text { kipas angin yang rusak, } \\
\text { menambah kantin untuk } \\
\text { pelanggan membeli makanan } \\
\text { dan beristirahat dan selalu } \\
\text { menjaga kebersihan toilet dan } \\
\text { mushola. }\end{array}$ \\
\hline $\begin{array}{l}\text { Kecepatan } \\
\text { dalam } \\
\text { merespon } \\
\text { pelanggan }\end{array}$ & $\begin{array}{l}\text { Petugas yang baik dalam } \\
\text { memberi pelayanan kepada } \\
\text { pelanggan, Menanggapi keluhan } \\
\text { dan masalah pelanggan dengan } \\
\text { cepat, baik dan ramah. } \\
\text { pelanggan juga senang dan } \\
\text { puas kepada pelayanan yang } \\
\text { diberikan. }\end{array}$ \\
\hline
\end{tabular}

(Sumber: Pengolahan Data, 2019
Dari hasil usulan perbaikan menggunakan metode TRIZ didapatkan usulan seperti diatas, kemudian untuk selanjutnya usulan perbaikan dari pendapat ahli di Stasiun Klaten didapatkan dengan wawancara secara langsung kepada salah satu pihak Stasiun Klaten, ditunjukan pada Tabel 11.

Tabel 11. Usulan Perbaikan Dari Pendapat Ahli di Stasiun Klaten

\begin{tabular}{|c|c|}
\hline Atribut & Usulan Perbaikan \\
\hline $\begin{array}{l}\text { Pelayanan } \\
\text { tiket cepat }\end{array}$ & $\begin{array}{l}\text { Memberi nomer antrian kepada } \\
\text { para pelanggan saat membeli } \\
\text { tiket dan menyiapkan mekanik } \\
\text { mesin tiket agar selalu siap bila } \\
\text { sewaktu-waktu mesin tiket error, } \\
\text { karena penyebab pelayanan } \\
\text { tiket tidak cepat di sebabkan } \\
\text { oleh mesin tiket yang sering } \\
\text { error. }\end{array}$ \\
\hline $\begin{array}{l}\text { Mesin tiket } \\
\text { tidak error }\end{array}$ & $\begin{array}{l}\text { Menyiapkan mekanik untuk } \\
\text { perawatan rutin mesin tiket dan } \\
\text { selalu dalam pengawasan } \\
\text { penjaga tiket agar bisa } \\
\text { memandu calon penumpang } \\
\text { yang membeli tiket. Karena } \\
\text { mesin error terjadi karena } \\
\text { penumpang kurang begitu } \\
\text { paham saat mengoperasikan } \\
\text { mesin tiket (seperti salah dalam } \\
\text { memasukan uang pada mesin } \\
\text { tiket) }\end{array}$ \\
\hline $\begin{array}{l}\text { Kursi } \\
\text { penumpang } \\
\text { dan } \\
\text { pengantar }\end{array}$ & $\begin{array}{l}\text { Menambah jumlah kursi untuk } \\
\text { calon penumpang dan } \\
\text { pengantar. }\end{array}$ \\
\hline $\begin{array}{l}\text { Fasilitas } \\
\text { penunjang }\end{array}$ & $\begin{array}{l}\text { Menambah fasilitas penunjang } \\
\text { yang belum ada dilingkungan } \\
\text { Stasiun Klaten dan menjaga } \\
\text { kebersihan lingkungan Stasiun } \\
\text { Klaten. }\end{array}$ \\
\hline $\begin{array}{l}\text { Kecepatan } \\
\text { dalam } \\
\text { merespon } \\
\text { pelanggan }\end{array}$ & $\begin{array}{l}\text { Petugas Stasiun mempunyai } \\
\text { sifat dan kepribadian sendiri- } \\
\text { sendiri, untuk itu PT KAI akan } \\
\text { memberi penyuluhan kepada } \\
\text { para petugas Stasiun Klaten } \\
\text { agar lebih disiplin dan } \\
\text { mengutamakan pelayanan yang } \\
\text { terbaik kepada para pelanggan. }\end{array}$ \\
\hline
\end{tabular}

(Sumber: Pengolahan Data, 2019 
Dapat dilihat dari kedua usulan perbaikan dengan metode TRIZ dan wawancara secara langsung kepada pihak Stasiun Klaten, hasil yang didapatkan untuk kedua usulan sama yaitu bertujuan untuk memperbaiki kualitas pelayanan yang ada di Stasiun Klaten untuk kedepannya. Dari kedua usulan perbaikan tersebut peneliti memilih usulan perbaikan dari pihak Staiun Klaten karena hasil yang didapatkan yaitu dengan wawancara secara langsung kepada salah satu pihak Stasiun Klaten.

\section{SIMPULAN}

Berdasarkan analisis hasil dan pembahasan, maka kesimpulan dari penelitian ini adalah sebagai berikut:

1. Dalam perhitungan Importance Performance Analysis dan diagram kartesius menunjukan bahwa ada 5 atribut kualitas yang tergolong dalam kuadran prioritas utama yang harus ditingkatkan kualitas pelayananya. Atribut kualitas tersebut terdiri dari:

a. Atribut kualitas nomor 6 dimensi Reliability (kendalan), yaitu pada atribut pelayanan tiket cepat dengan nilai tingkat kesesuaian atribut kualitas sebesar $44,45 \%$.

b. Atribut kualitas nomor 7 dimensi Reliability (kendalan) yaitu pada atribut Mesin tiket selalu dalam konsisi baik tidak error dengan nilai tingkat kesesuaian atribut kualitas sebesar $50,00 \%$.

c. Atribut kualitas nomor 12 dimensi Tangibles (bukti fisik) yaitu pada atribut Kursi bagi calon penumpang dan pengantar memadai dengan nilai tingkat kesesuaian atribut kualitas sebesar $48,24 \%$.

d. Atribut kualitas nomor 20 dimensi Tangibles (bukti fisik) yaitu pada atribut Fasilitas penunjang pelayanan lengkap dan memadai (ruang tunggu, kipas angin, toilet, mushola, kantin) dengan nilai tingkat kesesuaian atribut kualitas sebesar $55,14 \%$.

e. Atribut kualitas nomor 21 dimensi Responsivenes (Daya Tanggap) yaitu pada atribut Kecepatan dalam merespon keluhan dan permasalahan pelanggan dengan nilai tingkat kesesuaian atribut kualitas sebesar $58,19 \%$.

2. Usulan peningkatan kualitas pelayanan di Stasiun Klaten dengan metode Teoriya Resheniya Izobreatatelskikh Zadatch (TRIZ) dapat diketahui pada tahapan TRIZ yaitu solution selection. Terdapat 5 usulan perbaikan yang harus ditingkatkan oleh pihak Stasiun, dalam usulan perbaikan ini diambil dari pendapat ahli dari pihak Stasiun Klaten yaitu:

a. Antara lain memberi nomer antrian kepada para pelanggan saat membeli tiket dan menyiapkan mekanik mesin tiket agar selalu siap bila sewaktuwaktu mesin tiket error, karena penyebab pelayanan tiket tidak cepat di sebabkan oleh mesin tiket yang sering error.

b. Menyiapkan mekanik untuk perawatan rutin mesin tiket dan selalu dalam pengawasan penjaga tiket agar bisa memandu calon penumpang yang membeli tiket karena mesin error terjadi karena penumpang kurang begitu paham saat mengoperasikan mesin tiket (seperti salah dalam memasukan uang pada mesin tiket).

c. Menambah jumlah kursi untuk calon penumpang dan pengantar.

d. Menambah fasilitas penunjang yang belum ada dilingkungan Stasiun Klaten dan menjaga kebersihan lingkungan Stasiun Klaten.

e. PT KAl akan memberi penyuluhan kepada para petugas Stasiun Klaten agar lebih disiplin dan mengutamakan pelayanan yang terbaik kepada para pelanggan.

Saran

Dilihat dari hasil pembahasan dan kesimpulan, berikut adalah saran pada penelitian ini adalah :

1. Pihak Stasiun Klaten sebaiknya meningkatkan service performance kepada para pengguna jasa kerea api agar kepuasan semakin tinggi. Hal ini dapat dilakukan dengan cara memperbaiki tingkat pelayanan dan fasilitas yang masih dikeluhkan oleh penumpang. 
2. Pihak Stasiun Klaten harus mampu meningkatkan kepuasan konsumen secara terus-menerus dengan cara melakukan peningkatan kualitas pelayanan dengan mengidentifikasi kebutuhan dan keinginan konsumen, dikarenakan index kepuasan masyarakat tergolong sangat buruk.

3. Sebaiknya PT KAI melakukan upaya meningkatkan pelayanan agar kualitas pelayanan Stasiun Klaten lebih baik lagi.

\section{DAFTAR PUSTAKA}

Aritonang. L. R. (2005). Kepuasan Pelanggan. Jakarta: PT Gramedia Pustaka Utama.

Devani.V., dan Rizko.R.A. (2016). Analisis Kepuasan Pelanggan dengan MenggunakanMetode Customer Satisfaction Index (CSI) Dan Potential Gain In Customer Value (PGCV). Yogyakarta. Jurnal Rekayasa Dan Manajemen Sistem Informasi, Vol. 2, No. 2. PP 24-29.

Dharmawan. A., dan Febriana. W. (2014). Rancangan Perbaikan Kualitas Pelayanan Jasa Dengan Metode Servqual, Importance Performance Analysis, dan Quality Function Deployment Pada Cabang Telkom Diyono Cabang Surabaya. Surabaya. Jurnal Manajemen Teori Dan Terapan, Vol. 7, No. 3. PP 207-223.

Dharmayanti. D.(2006). Analisis Dampak Service Performance dan Kepuasan Sebagai Moderating Variable Terhadap Loyalitas Nasabah, Jurnal Manajemen Pemasaran. PP 35-43.

Efranto.R. Y., Singgih. M. L., dan Suef. M. (2008). Evaluasi Model Peningkatan Kualitas PelayananDengan Pendekatan Servperf,Six Sigma(Studi Kasus: Kantor Bersama Samsat Manyar Surabaya Timur). Surabaya.Prosiding Seminar Nasional Manajemen Teknologi VIII.PP A.23.1-A23-10.

Handriati. A.A., Sunaryo., dan Vebri.N.H. (2015). Analisa Kepuasan Pelayanan Publik Terhadap Kepuasan Konsumen Dengan Menggunakan Metode Servperf-IPA-CSI. Yogyakarta. Jurnal Teknologi Informasi. Vol. 21, No. 4. PP 178-190.

Hidayati. S.N., dan Prasetyo. A.P.
(2015). Analisis Kualitas Pelayanan eKTP Menggunakan Metode Customer Satifaction Index, Metode Service Quality, dan Importance Performance Analysis. Yogyakarta. Jurnal Maskipreneur. Vol 5, No. 1. PP 117-133. Hudaya dan Medina, A.R. (2011).Peningkatan Kualitas Pelayanan Di Unit Farmasi Rawat Jalan Berdasarkan Tingkat Kepuasan Pelanggan Menggunakan Pendekatan Lean Servperf.Journal of Industrial Research. PP 27-36.

Kotler. P. (2003). Marketing Management. The Millenium Edition. New Jersey: Prentice Hall.

Musanto. T. (2004). Faktor-Faktor Kepuasan Pelanggan dan Loyalitas Pelanggan. Jurnal Manajemen \& Kewirausahaan. Vol. 6, No. 2. PP 123136.

Panjaitan, J. E. 2016. Pengaruh Kualitas Pelayanan Terhadap Kepuasan Pada Pelanggan JNE Cabang Bandung. DeReMa Jurnal Manajemen. 11 (2) : 265-289.

Rachmansyah. A. (2013). Pengaruh Kualitas Pelayanan terhadap Kepuasan Konsumen pada PT. Dok dan Perkapalan Surabaya (Persero).

Rahmanti. H. W., Effendi. U., danAstuti. R. (2017). Analysis of Quality Service Improvement using Servqual and TRIZ Method (Case Study "Ocean Garden Restaurant'. Malang. Jurnal Teknologi Pertanian.Vol. 18, No. 1. PP 33-44.

Sari. D. P., dan Hermawan. A (2012). Usulan Perbaikan Kualitas Pelayanan pada Instalasi Rawat Jalan Dengan Metode Servqual dan TRIZ di RS Muhammadiyah Roemani. Jurnal J@TI Undip. Vol. 7, No. 2. PP 95-104.

Setyaningsih. I. (2013). Analisis Kualitas Rumah Sakit Terhadap Pasien Menggunakan Pendekatan Lean Servperf Dan Service Performace. (Studi Kasus: Rumah Sakit X). Jurnal Spektrum Industri Vol. 11, No. 2. pp. 117-242.

Sugiyono. (2007). Metode Penelitian Administasi. Bandung: Alvabeta.

Suhendra. A., dan Dwi. P. (2016). Kajian Tingkat Kepuasan Pengguna Trans 
Metro Bandung Koridor 2 Dengan Menggunakan Pendekatan Importance Performance Analysis. Bandung. Jurnal Teknik Sipil Itenas. Vol. 2, No. 2. PP 112.

Tjiptono, Fandi. 2012. Service Management Mewujudkan Layanan Prima Edisi:2. Yogyakarta : Penerbit Andi.

Yola, M dan Budianto, D. 2013.Analisis Kepuasaan Konsumen Terhadap Kualitas Pelayanan Dan Harga Produk Pada Supermarket Dengan Menggunakan Metode Importance Performance Analysis (IPA).Jurnal Optimasi Sistem Industri. 12 (12) : 301309 